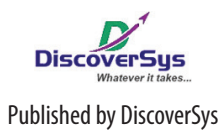

Published by DiscoverSys

\section{Workload Analysis of Doctors at Puskesmas Using Workload Indicators of Staffing Need in Denpasar}

\author{
Anak Agung Ngurah Gede Dharmayuda, ${ }^{1 *}$ Luh Putu Lila Wulandari, ${ }^{1,2}$ \\ Dewa Nyoman Wirawan ${ }^{1,3}$
}

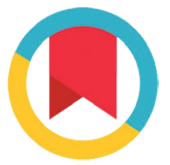

CrossMark
Background and purpose: Ratio of health staffinstead of workload have been used to determine quota of staff at primary health centers. There is no study assessing workload of functional medical doctors (general practitioners) at primary health centers in Bali. The objectives of this study were to describe functional medical doctors workload, the number and distribution which is needed in primary health centers in Denpasar.

Methods: Descriptive cross-sectional study was conducted among functional medical doctors at 11 primary health centers across Denpasar. Data were collected by interview and participatory observation to the study participants. Data was analyzed using WISN English Version 1.1.132.0 software.
Results: Among 34 study participants, majority were female (73.5\%), aged 35-44 years (61.8\%), working as a government employee $(97.1 \%)$, with tenure of $6-10$ years $(55.9 \%)$ and almost all of them (95.6\%) had additional duties besides providing medical care to patients. Results indicated that workload of functional medical doctors at primary health centers was high with WISN ratio 0.5-0.9 compared to the ideal ratio $=1$. Based on workload analysis, shortages of functional medical doctors was found in all primary health centers in Denpasar. Conclusion: When using the ratio of functional medical doctors per population, the number was sufficient. However, when using workload analysis indicated shortage.

Keywords: workload, functional medical doctors, primary health centers, WISN

Cite This Article: Dharmayuda, A.A.N.G., Wulandari, L.P.L., Wirawan, D.N. 2015. Workload Analysis of Doctors at Puskesmas Using Workload Indicators of Staffing Need in Denpasar. Public Health and Preventive Medicine Archive 3(1): 16-21. D0l:10.15562/phpma.v3i1.95

\title{
Analisis Beban Kerja Dokter Umum di Puskesmas Kota Denpasar dengan Menggunakan Metode Workload Indicators of Staffing Need
}

${ }^{1}$ Public Health Postgraduate Program Udayana University, ${ }^{2} S$ chool of Public Health Faculty of Medicine Udayana University, ${ }^{3}$ Department of Community and Preventive Medicine Faculty of Medicine Udayana University

*Correspondence to: Anak Agung Ngurah Gede Dharmayuda, Public Health Postgraduate Program Udayana University

drdharmayuda@gmail.com
Hasil: Sebagian besar dari 34 dokter umum di puskesmas yang menjadi sampel penelitian adalah perempuan $(73,5 \%)$, berumur 35-44 tahun $(61,8 \%)$, status pegawai negeri $(97,1 \%)$, masa kerja 6-10 tahun $(55,9 \%)$ dan hampir semuanya $(95,6 \%)$ mempunyai tugas tambahan selain memberikan pelayanan kepada pasien. Hasil analisis menunjukkan bahwa beban kerja dokter umum di puskesmas Kota Denpasar termasuk kategori tinggi dengan rasio 0,5-0,9. Beban kerja yang dianggap sesuai adalah bila rasio beban kerja sama dengan satu. Bila dilihat dari analisis beban kerja ditemukan bahwa semua puskesmas di Kota Denpasar mengalami kekurangan dokter umum dengan jumlah kekurangan yang bervariasi.

Simpulan: Bila menggunakan perhitungan rasio per jumlah penduduk, jumlah dokter umum di puskesmas Kota Denpasar telah mencukupi, namun dari hasil analisis beban kerja dijumpai masih adanya kekurangan. 


\section{PENDAHULUAN}

Dokter umum merupakan sumber daya manusia (SDM) kesehatan yang masih menjadi perhatian penting terkait ketersediaan dan distribusinya yang tidak merata. Dari 106.370 dokter umum yang ada di Indonesia hanya 17.507 orang yang bekerja di puskesmas. ${ }^{1}$ Berdasarkan data sampai dengan Oktober 2013, puskesmas yang memiliki dokter umum hanya 13,7\% dari 9.599 puskesmas di Indonesia. ${ }^{2}$ Kekurangan dokter umum di puskesmas terjadi karena kurangnya minat dokter untuk bekerja di daerah terpencil. Hal ini kemungkinan karena secara ekonomi bekerja di perkotaan dan sektor swasta dirasakan lebih menguntungkan dibanding di pedesaan atau di puskesmas. Terbatasnya pengangkatan dokter pegawai tidak tetap (PTT) juga merupakan salah satu faktor kurangnya tenaga dokter umum di puskesmas. Terbatasnya pengembangan karir pasca PTT seperti kesulitan mendapat peluang menjadi calon pegawai negeri sipil (CPNS), terbatasnya peluang untuk pendidikan spesialis dan kurangnya informasi karir pasca PTT juga menurunkan minat lulusan dokter baru untuk menjadi dokter PTT. ${ }^{3}$ Berdasarkan catatan di Dinas Kesehatan Kota Denpasar jumlah dokter umum yang memberikan pelayanan kesehatan kepada masyarakat di Kota Denpasar berjumlah sebanyak 348 orang dan 44 orang diantaranya bekerja di 11 puskesmas terdiri dari 34 orang dokter umum fungsional dan 10 orang struktural (kepala puskesmas). ${ }^{4}$

Selama ini perencanaan kebutuhan tenaga dokter umum puskesmas di Kota Denpasar dilakukan dengan memakai rasio (perbandingan) jumlah dokter umum per jumlah penduduk. Bila berdasarkan rasio maka jumlah dokter umum di Kota Denpasar adalah 40,4 per 100.000 penduduk dan rasio ini menunjukkan bahwa jumlah dokter umum yang dibutuhkan sudah melebihi dari standar yang ditetapkan yaitu 40 per 100.000 penduduk. Kondisi yang hampir sama dijumpai pada beberapa negara di Asia seperti di Thailand sebesar 41 per 100.000 penduduk, ${ }^{5}$ Bangladesh sebesar 40,4 per 100.000 penduduk $^{6}$ dan Vietnam sebesar 45 per 100.000 penduduk.?

Namun rasio ini tidak menunjukkan kebutuhan dokter umum bila didasarkan dengan beban kerja nyata di puskesmas. Jika dilihat dari rasio jumlah dokter umum terhadap kunjungan pasien ke poliklinik umum, rasio yang didapat untuk puskesmas di Denpasar sangat kecil, yaitu 7,1 per 100.000 penduduk. Namun belum ada standar yang mengatur tentang pemakaian rasio tersebut dalam perencanaan kebutuhan tenaga dokter. ${ }^{4}$ Metode yang paling obyektif dalam perencanaan kebutuhan tenaga dokter adalah memperhitungkan beban kerja dokter umum dengan melakukan analisis beban kerja. $^{8}$

Keinginan untuk mempergunakan analisis beban kerja sudah sejak lama muncul di Indonesia, namun sampai saat ini masih belum banyak diterapkan. Dalam Kepmenkes No. 81 Tahun 2004 tentang Pedoman Penyusunan Perencanaan SDM Kesehatan di Tingkat Provinsi, Kabupaten/ Kota serta Rumah Sakit, disebutkan bahwa salah satu cara dalam perencanaan kebutuhan tenaga kesehatan di institusi adalah berdasarkan beban kerja dengan menggunakan metode Workload Indicators of Staffing Need (WISN). Metode WISN merupakan penghitungan kebutuhan tenaga kesehatan berdasarkan beban kerja nyata yang dilaksanakan oleh setiap kategori tenaga kesehatan pada tiap unit kerja di fasilitas pelayanan kesehatan. ${ }^{9}$ Sampai saat ini, metode WISN belum banyak digunakan dalam penghitungan kebutuhan tenaga dokter umum berdasarkan beban kerja di Indonesia dan sama sekali belum pernah dilakukan di Provinsi Bali khususnya di Kota Denpasar. Di lain pihak pemerintah telah mengeluarkan Permenkes Nomor 75 Tahun 2014 tentang Pusat Kesehatan Masyarakat yang mana dalam perencanaan SDM kesehatan harus melalui penghitungan beban kerja. ${ }^{8}$

Tujuan penelitian ini adalah untuk mengetahui beban kerja, kebutuhan tenaga dokter umum serta distribusinya di puskesmas Kota Denpasar.

\section{METODE}

Penelitian ini menggunakan rancangan deskriptif cross-sectional yang dilaksanakan mulai Oktober 2014 sampai dengan Maret 2015 pada semua dokter umum fungsional di puskesmas Kota Denpasar yang berjumlah 34 dokter.

Mengacu pada pedoman dari WISN WHO tahun 2010, terdapat beberapa variabel yang dianalisis yaitu kategori tenaga kesehatan, waktu kerja tersedia (WKT), komponen beban kerja, aktivitas standar, standar beban kerja, faktor kelonggaran dan kebutuhan tenaga. ${ }^{9}$

Pengumpulan data dilakukan dengan menggunakan pedoman observasi, stopwatch, serta formulir pencatatan untuk data sekunder. Analisis data kuantitatif dilakukan dengan menggunakan software WISN English Version 1.1.132.0. Data disajikan dalam bentuk tabel dan narasi.

Prosedur pelaksanaan penelitian dimulai dengan pelaksanaan lokakarya yang melibatkan dokter umum fungsional dari seluruh puskesmas Kota Denpasar dengan tujuan untuk merumuskan waktu kerja yang tersedia per tahun dan komponen beban kerja atau aktivitas untuk tiap kategori dokter umum. Selanjutnya dilakukan pelatihan pada enam 
petugas pengamat yang direkrut tentang pengantar WISN, jenis kegiatan sebagai komponen beban kerja dokter umum, serta cara melakukan observasi. Observasi dilakukan di masing-masing puskesmas untuk validasi data hasil lokakarya. Observasi dilaksanakan sebanyak tiga kali per puskesmas dengan memilih variasi jumlah kunjungan pasien ke puskesmas yaitu hari dengan kunjungan tertinggi (Senin), sedang (Rabu) dan hari dengan kunjungan terendah (Jumat). Waktu rata-rata yang didapat untuk setiap aktivitas sesuai komponen beban kerja yang dapat diobservasi dijadikan sebagai standar waktu dalam penghitungan beban kerja dengan menggunakan software WISN dan dijadikan sebagai standar waktu khusus bagi dokter umum di puskesmas Kota Denpasar. Terakhir, pengumpulan data sekunder dengan melihat laporan kunjungan pasien, buku rencana kerja pegawai, daftar kehadiran dan dokumen terkait lainnya.
Penelitian ini telah mendapat kelaikan etik dari Komisi Etik Penelitian Fakultas Kedokteran Universitas Udayana/ Rumah Sakit Umum Pusat Sanglah Denpasar.

\section{HASIL}

Jumlah dokter umum yang diobservasi dan diwawancaraiberjumlah34 orang. Pada Tabel 1 dapat dilihat bahwa sebagian besar dokter umum berada pada kelompok umur 35-44 tahun yaitu sebanyak 21 orang $(61,8 \%)$. Berdasarkan karakteristik jenis kelamin, lebih banyak berjenis kelamin perempuan yaitu sebanyak 25 orang (73,5\%). Hampir semua dokter umum adalah Pegawai Negeri Sipil (PNS) yaitu sebanyak 33 orang $(97,1 \%)$ dan satu orang dengan status pegawai kontrak. Berdasarkan lama bekerja, sebanyak 19 orang $(55,9 \%)$ sudah bekerja selama 6-10 tahun. Sebanyak 23 orang (51,1\%)

Tabel 1 Karakteristik dokter fungsional puskesmas (dokter umum) Kota Denpasar tahun 2014

\begin{tabular}{|c|c|c|c|c|c|c|c|c|c|c|}
\hline \multirow[b]{3}{*}{ Karakteristik } & \multicolumn{8}{|c|}{ Kecamatan } & & \\
\hline & \multicolumn{2}{|c|}{ Denpasar Timur } & \multicolumn{2}{|c|}{ Denpasar Barat } & \multicolumn{2}{|c|}{ Denpasar Utara } & \multicolumn{2}{|c|}{ Denpasar Selatan } & \multicolumn{2}{|c|}{ Total } \\
\hline & $\mathbf{n}$ & $\%$ & $\mathbf{n}$ & $\%$ & $\mathbf{n}$ & $\%$ & $\mathbf{n}$ & $\%$ & $\mathbf{n}$ & $\%$ \\
\hline \multicolumn{11}{|l|}{ Umur } \\
\hline $26-34$ th & 1 & 16,7 & 3 & 50,0 & 1 & 11,1 & 3 & 23,1 & 8 & 23,5 \\
\hline $35-44$ th & 3 & 50,0 & 3 & 50,0 & 6 & 60,0 & 9 & 75,0 & 21 & 61,8 \\
\hline $45-54$ th & 0 & 0,0 & 0 & 0,0 & 1 & 11,1 & 0 & 0,0 & 1 & 9,0 \\
\hline$>55$ & 2 & 33,3 & 0 & 0,0 & 2 & 22,2 & 0 & 0,0 & 4 & 11,8 \\
\hline \multicolumn{11}{|l|}{ Jenis kelamin } \\
\hline Perempuan & 5 & 83,3 & 5 & 83,3 & 8 & 80,0 & 7 & 58,3 & 25 & 73,5 \\
\hline Laki-laki & 1 & 16,7 & 1 & 16,7 & 2 & 20,0 & 5 & 41,7 & 9 & 26,5 \\
\hline \multicolumn{11}{|l|}{ Status pegawai } \\
\hline PNS & 6 & 100,0 & 6 & 100,0 & 9 & 90,0 & 12 & 100,0 & 33 & 97,1 \\
\hline Kontrak & 0 & 0,0 & 0 & 0,0 & 1 & 10,0 & 0 & 0,0 & 1 & 2,9 \\
\hline \multicolumn{11}{|l|}{ Lama bekerja } \\
\hline$<5$ th & 2 & 33,3 & 2 & 33,3 & 2 & 20,0 & 3 & 25,0 & 9 & 26,5 \\
\hline $6-10$ th & 3 & 50,0 & 4 & 66,7 & 5 & 50,0 & 7 & 58,3 & 19 & 55,9 \\
\hline $11-15$ th & 0 & 0,0 & 0 & 0,0 & 0 & 0,0 & 1 & 8,3 & 1 & 2,9 \\
\hline$>15$ th & 1 & 16,7 & 0 & 0,0 & 3 & 30,0 & 1 & 8,3 & 5 & 14,7 \\
\hline \multicolumn{11}{|l|}{ Program yang dipegang } \\
\hline Koordinator program & 4 & 57,1 & 3 & 33,3 & 7 & 53,8 & 9 & 56,3 & 23 & 51,1 \\
\hline Bendahara BOK & 0 & 0,0 & 0 & 0,0 & 0 & 0,0 & 1 & 6,3 & 1 & 2,2 \\
\hline Bendahara JKN & 0 & 0,0 & 0 & 0,0 & 0 & 0,0 & 1 & 6,3 & 1 & 2,2 \\
\hline Bendahara JKBM & 0 & 0,0 & 0 & 0,0 & 1 & 7,7 & 1 & 6,3 & 2 & 4,4 \\
\hline Lain-lain & 3 & 42,9 & 5 & 55,6 & 5 & 38,5 & 3 & 18,8 & 16 & 35,6 \\
\hline Tidak ada & 0 & 0,0 & 1 & 11,1 & 0 & 0,0 & 1 & 6,3 & 2 & 4,4 \\
\hline \multicolumn{11}{|l|}{ Praktik mandiri } \\
\hline $\mathrm{Ya}$ & 4 & 66,7 & 2 & 33,3 & 7 & 70,0 & 7 & 58,3 & 20 & 58,8 \\
\hline Tidak & 2 & 33,3 & 4 & 66,7 & 3 & 30,0 & 5 & 41,7 & 14 & 41,2 \\
\hline
\end{tabular}


Tabel 2 Beban kerja dokter fungsional puskesmas (dokter umum) Kota Denpasar tahun 2014

\begin{tabular}{|c|c|c|c|c|c|c|}
\hline Nama puskesmas & $\begin{array}{c}\text { Jumlah dokter } \\
\text { yang ada }\end{array}$ & $\begin{array}{l}\text { Jumlah dokter } \\
\text { menurut WISN }\end{array}$ & $\begin{array}{c}\text { Kekurangan tenaga } \\
\text { dokter }\end{array}$ & $\begin{array}{c}\text { Masalah tenaga } \\
\text { kerja }\end{array}$ & Rasio WISN & $\begin{array}{c}\text { Tekanan beban } \\
\text { kerja }\end{array}$ \\
\hline \multicolumn{7}{|l|}{ Denpasar Timur } \\
\hline I & 4 & 6 & -2 & Kekurangan & 0,62 & Tinggi \\
\hline II & 2 & 3 & -1 & Kekurangan & 0,72 & Tinggi \\
\hline \multicolumn{7}{|l|}{ Denpasar Barat } \\
\hline I & 2 & 3 & -1 & Kekurangan & 0,85 & Tinggi \\
\hline II & 4 & 8 & -4 & Kekurangan & 0,50 & Tinggi \\
\hline \multicolumn{7}{|l|}{ Denpasar Utara } \\
\hline I & 3 & 5 & -2 & Kekurangan & 0,63 & Tinggi \\
\hline II & 3 & 5 & -2 & Kekurangan & 0,67 & Tinggi \\
\hline III & 4 & 5 & -1 & Kekurangan & 0,90 & Tinggi \\
\hline \multicolumn{7}{|l|}{ Denpasar Selatan } \\
\hline I & 3 & 4 & -1 & Kekurangan & 0,75 & Tinggi \\
\hline II & 2 & 3 & -1 & Kekurangan & 0,61 & Tinggi \\
\hline III & 2 & 3 & -1 & Kekurangan & 0,75 & Tinggi \\
\hline IV & 5 & 7 & -2 & Kekurangan & 0,70 & Tinggi \\
\hline
\end{tabular}

Tabel 3 Distribusi dokter fungsional puskesmas (dokter umum) Kota Denpasar tahun 2014

\begin{tabular}{|c|c|c|c|c|c|}
\hline Nama puskesmas & $\begin{array}{c}\text { Jumlah desa atau } \\
\text { kelurahan }\end{array}$ & $\begin{array}{c}\text { Jumlah } \\
\text { penduduk }\end{array}$ & $\begin{array}{c}\text { Kepadatan } \\
\text { penduduk }\left(\mathbf{k m}^{2}\right)\end{array}$ & $\begin{array}{l}\text { Jumlah } \\
\text { pustu }\end{array}$ & Jumlah dokter umum \\
\hline \multicolumn{6}{|l|}{ Denpasar Timur } \\
\hline I & 6 & 74.528 & 9.924 & 2 & 4 \\
\hline II & 5 & 63.354 & 4.669 & 4 & 2 \\
\hline \multicolumn{6}{|l|}{ Denpasar Barat } \\
\hline I & 5 & 103.360 & 9.733 & 3 & 2 \\
\hline II & 6 & 106.840 & 7.902 & 4 & 4 \\
\hline \multicolumn{6}{|l|}{ Denpasar Utara } \\
\hline I & 4 & 51.308 & 10.134 & 1 & 3 \\
\hline II & 3 & 70.831 & 6.972 & 2 & 3 \\
\hline III & 4 & 60.308 & 3.537 & 3 & 4 \\
\hline \multicolumn{6}{|l|}{ Denpasar Selatan } \\
\hline I & 3 & 89.116 & 6.519 & 2 & 3 \\
\hline II & 4 & 42.252 & 3.223 & 3 & 2 \\
\hline III & 2 & 40.169 & 2.744 & 1 & 2 \\
\hline IV & 1 & 26.958 & 3.599 & 0 & 5 \\
\hline
\end{tabular}

adalah sebagai koordinator program. Selain praktek di puskesmas sebanyak 20 orang $(58,8 \%)$ memiliki praktek mandiri. Waktu kerja yang telah disepakati pada saat lokakarya dengan dokter umum adalah sebanyak 52 minggu setahun, enam hari per seminggu, 5,8 jam per hari.

Pada Tabel 2 disajikan beban kerja dokter umum di masing-masing puskesmas. Terlihat bahwa bahwa semua puskesmas memiliki beban kerja yang tinggi dengan rasio WISN 0,5-0,9 dan mengalami kekurangan dokter umum. Kekurangan dokter umum yang paling banyak yaitu di Puskesmas II Denpasar Barat sebanyak 4 dokter umum. Puskesmas ini adalah puskesmas rawat inap dengan beban kerja dokter umum kategori tinggi, sedangkan puskesmas lainnya hanya kekurangan satu sampai dua dokter.

Pada Tabel 3 disajikan distribusi dokter fungsional puskesmas (dokter umum) di Kota Denpasar. Terlihat bahwa jumlah dokter umum 
tidak seimbang di setiap puskesmas berdasarkan jumlah desa/ kelurahan dan penduduk yang dilayani. Jumlah dokter umum terbanyak terdapat di Puskesmas IV Denpasar Selatan yaitu lima orang. Jika dilihat dari jumlah desa/ kelurahan yang dilayani, Puskesmas IV Denpasar Selatan hanya melayani satu desa/kelurahan. Dilain pihak Puskesmas I Denpasar Timur dan Puskesmas II Denpasar Barat melayani enam desa/kelurahan. Jumlah penduduk yang dilayani paling banyak di wilayah kerja Puskesmas II Denpasar Barat dan paling sedikit di wilayah kerja Puskesmas IV Denpasar Selatan. Ketersediaan fasilitas pelayanan puskesmas pada umumnya juga didukung oleh keberadaan puskesmas pembantu (pustu) kecuali di Puskesmas IV Denpasar Selatan yang tidak memiliki pustu.

\section{DISKUSI}

Berdasarkan Permenkes Nomor 75 Tahun 2014 perencanaaan SDM kesehatan sebaiknya dengan penghitungan beban kerja dibandingkan rasio per penduduk. ${ }^{8}$ Untuk Kota Denpasar dokter umum fungsional puskesmas saat ini berjumlah 34 orang dengan rasio 40,4/100.000 penduduk. Bila dilihat angka ini terlihat bahwa jumlah dokter umum fungsional di puskesmas telah mencukupi. Namun bila mempertimbangkan beban kerja dengan metode WISN jumlah yang diperlukan adalah 52 orang. Dengan demikian di Kota Denpasar ada kekurangan sebanyak 18 orang. Hal ini disebabkan karenajumlah pasien yang berkunjungkepuskesmas cukup tinggi sedangkan dokter umum fungsional juga mempunyai tugas-tugas lain. Penelitian lain tentang beban kerja dokter umum yang dilakukan oleh Rusli tahun 2013 menyatakan bahwa beban kerja dokter umum di poli umum sangat tinggi bila dibandingkan dengan jumlah pasien yang harus dilayani dan waktu kerja tersedia. ${ }^{9}$ Beban kerja yang berlebih dapat mempengaruhi kinerja dokter dalam memberikan pelayanan kesehatan seperti ketepatan diagnosis dan tindakan medis. ${ }^{10,11,12}$

Selain itu distribusi dokter umum fungsional di puskesmas Kota Denpasar juga tidak merata dan hal ini akan bisa diatasi bila dokter umum fungsional yang diperlukan ditempatkan berdasar perhitungan beban kerja. Kekurangan dokter di Kota Denpasar dalam jangka pendek bisa diatasi dengan adanya penempatan dokter internship oleh pemerintah. $^{13}$

Penelitian ini dilakukan hanya di Kota Denpasar dan karena itu hasilnya tidak bisa digeneralisir ke wilayah lainnya baik di Bali maupun wilayah lain di Indonesia. Kelemahan lainnya adalah kemungkinan adanya bias pada saat melakukan observasi oleh observer. Pelaksanaan observasi seharusnya dilakukan dalam waktu yang lebih panjang sehingga semua komponen beban kerja dapat divalidasi. Komponen beban kerja yaitu KIE/konsultasi tidak tercatat dengan baik oleh dokter umum di puskesmas sehingga tidak bisa dihitung dalam analisis padahal KIE/konsultasi merupakan aktivitas yang sangat penting untuk dilaksanakan oleh semua dokter umum. Selain itu kelengkapan data sekunder sangat menentukan dalam keberhasilan penghitungan.

Hasil penelitian ini diharapkan dapat dipakai sebagai pedoman bagi Dinas Kesehatan Kota Denpasar untuk merencanakan kebutuhan tenaga kesehatan khususnya dokter umum. Penelitian lebih lanjut diharapkan agar seluruh komponen beban kerja dokter umum dapat dihitung serta melakukan pengamatan aktivitas dokter umum secara penuh sehingga hasil analisis beban kerja akan lebih akurat.

\section{SIMPULAN}

Analisis beban kerja dokter umum di puskesmas Kota Denpasar menunjukkan hasil yang berbeda dibandingkan dengan memakai rasio dokter per jumlah penduduk. Beban kerja dokter umum di seluruh puskesmas Kota Denpasar dijumpai cukup tinggi dengan rasio WISN 0,5-0,9.

\section{UCAPAN TERIMA KASIH}

Ucapan terima kasih penulis sampaikan kepada seluruh dokter umum fungsional yang telah berpartisipasi dalam penelitian ini. Penulis juga menyampaikan ucapan terima kasih kepada seluruh Kepala Puskesmas se-Kota Denpasar dan semua pihak yang telah membantu pelaksanaan penelitian ini.

\section{DAFTAR PUSTAKA}

1. Kementerian Kesehatan RI. Data Dasar Puskesmas. Jakarta; 2013.

2. Kementerian Kesehatan RI. Pengembangan dan Pemberdayaan SDM Kesehatan dalam Persiapan Pelaksanaan JKN. Jakarta: BPPSDM Kesehatan; 2013.

3. Suwandono A, Setijadi G, Sumantri S. Hasil Awal Angket Dokter PTT. Media Litbang Kesehatan. 2003;12(4):23-9.

4. Dinas Kesehatan. Profil Kesehatan Kota Denpasar Tahun 2013. Denpasar; 2014.

5. WHO. Human Resources for Health Country Profile: Thailand. Geneva; 2010.

6. WHO. People's Republic of Bangladesh: Human Resources for Health Country Profile. Geneva; 2013.

7. Sanjeed V. Vietnam Healthcare - The Next Growth Frontier? Asia Pasific Biotech. 2009;13(10):18-24.

8. Peraturan Menteri Kesehatan Republik Indonesia Nomor 75 Tahun 2014. Pusat Kesehatan Masyarakat. 2014.

9. WHO. Workload Indicator Of Staffing Need. Geneva: WHO Press; 2010. 
10. Michtalik HJ, Yeh HC, Pronovost PJ, Brotman DJ. Impact of Attending Physician Workload on Patient Care: A Survey of Hospitalists. JAMA Intern Medicine. 2013;173(5):375-7.

11. Mudayana AA. Pengaruh Motivasi dan Beban Kerja Terhadap Kinerja Karyawan di Rumah Sakit Nur Hidayah Bantul. KES MAS. 2010;4(2):84-92.

12. Shah SSH, Jaffari AR, Aziz J, Ejaz W, Ul-Haq I, Raza SN. Workload and Performance of Employees. Interdisciplinary Journal of Contemporary Research Businnes. 2011;3(5):256-67.
13. Departemen Keseharan RI. Pedoman Pelaksanaan Internsip Dokter Indonesia. Buku 1. Jakarta: BPPSDM Kesehatan; 2009.

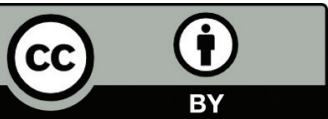

This work is licensed under a Creative Commons Attribution 